\title{
O concheiro do Meu Jardim (Nazaré) no contexto das estratégias de produção e circulação de suportes lâmino lamelares no Neolítico Médio da Estremadura Portuguesa
}

\author{
Eliana Goufa ${ }^{1}$, António Carlos Valera ${ }^{2}$, António Faustino Carvalho ${ }^{3}$
}

1. CEAACP - Centro de Estudos de Arqueologia, Artes e Ciências do Património (pólo UAlg), Universidade do Algarve, F.C.H.S., Campus de Gambelas, 8000-117 Faro, Portugal. Email: e.goufa.arq@gmail.com

2. ICArEHB - Interdisciplinary Center for Archaeology and Evolution of Human Behaviour / Era-Arqueologia Lda., Calçada de Santa Catarina, 9C, 1495-705 Lisboa, Portugal. Email: antoniovalera@era-arqueologia.pt

3. Universidade do Algarve, F.C.H.S., Campus de Gambelas, 8000-117 Faro, Portugal. Email: afcarva@ualg.pt

\section{Resumo:}

Na planície aluvial da várzea da Nazaré (província da Estremadura Portuguesa, na região centro litoral do país), numa área que estabelece o contacto entre o antigo estuário lagunar interior e o oceano, foi identificado um sítio arqueológico conhecido por Meu Jardim, datado do Neolítico Médio (finais do V e IV milénios A.N.E.), com diversos momento de ocupação registados em estratigrafia, e localizado nas proximidades das jazidas de sílex que terão provavelmente sido exploradas pelos seus ocupantes. Trata-se de um concheiro com vários níveis de ocupação de contexto doméstico.

Em face das lacunas de conhecimento que caracterizam os estudos líticos deste período, optou-se por analisar apenas, neste primeiro estudo, as suas produções lâmino-lamelares e integrá-las no contexto regional.

Estamos perante material de pequenas dimensões, sobretudo em sílex (o quartzo está menos representado), produzido a partir de núcleos prismáticos pré-formatados (o principal método de produção de suportes lâmino-lamelares), que teve lugar nas próprias jazidas de sílex exploradas na área envolvente. As lâminas e lamelas apresentam atributos compatíveis com uma debitagem por pressão, com talões facetados, e terão, no caso do Meu Jardim, sido utilizadas de modo expedito para suprir as necessidades decorrentes de estadias episódicas no local.

De um modo geral, as inferências produzidas a partir do material do sítio do Meu Jardim e da sua comparação com outros contextos revelam, para o período em causa, um comportamento económico e tecnológico muito diversificado no que respeita à exploração e circulação do sílex. As estratégias subjacentes a estas práticas parecem determinadas pela proximidade (maior ou menor) de jazidas de sílex e pelo fim a que se destinavam os suportes alongados (uso imediato, dilatado no tempo, ou uso como oferenda funerária).

Palavras-chave: Neolítico; Portugal; suportes lâmino-lamelares; tecnologia; sílex

Published by the School of History, Classics and Archaeology, University of Edinburgh ISSN: 2055-0472. URL: http://journals.ed.ac.uk/lithicstudies/

This work is licensed under a Creative Commons Attribution 2.5 UK: Scotland License. 


\section{Introdução}

Até a década de 1990, a análise lítica em Portugal tinha como objetivo a definição de fósseis diretores para, juntamente com outras categorias artefactuais (cerâmica, metalurgia), caracterizar fases ou períodos culturais. Para esse fim, recorria-se a produtos acabados (geométricos, pontas de seta, lâminas e lamelas, grandes foliáceos, etc.) tendo em vista a elaboração de tipologias mais ou menos detalhadas, fosse de regiões ou mesmo apenas de sítios singulares. Esta perspetivação teórica não era estranha à corrente de pensamento de raiz histórico-cultural então predominante. Diversos trabalhos continuavam persistentemente a tratar o talhe da pedra à maneira tradicional. Será apenas em meados daquela década que tem lugar uma viragem nos estudos das indústrias de pedra lascada neolíticas, em parte como resultado colateral da renovação dos estudos do Paleolítico Superior português operada nesse momento (Zilhão 1997), num alinhamento teórico bordesiano. Em particular, tiveram algum eco em Portugal as definições e critérios analíticos propostos por Tixier et al. (1980), os quais foram depois adaptados ao estudo da Pré-História recente e, mais especificamente, ao Neolítico (Carvalho 1998a; 2008; 2009a; 2012). Por essa razão, são esses os critérios que se adotam no presente trabalho.

O estudo do concheiro do Meu Jardim configura-se como muito relevante para o conhecimento do talhe da pedra durante o Neolítico médio da Estremadura Portuguesa porquanto a larga maioria dos trabalhos publicados até ao momento têm incidido principalmente em contextos da fase antiga do período. Com efeito, e como se verá nas conclusões, são poucos até ao momento os contextos do Neolítico médio tratados de acordo com as perspetivas teórico-metodológicas mais recentes. Além deste aspeto específico da investigação, salienta-se também o facto de estes contextos se revestirem por vezes de particularismos a vários níveis - quanto às matérias-primas dominantes, métodos de talhe empregues, circulação de suportes, variabilidade tipológica das utensilagens, etc. - que urge esclarecer e interpretar através da aquisição de novos dados de terreno.

Perante a multiplicidade de abordagens possíveis ao Meu Jardim, opta-se por centrar esta primeira análise no talhe lâmino-lamelar. Por uma questão de método, apresentam-se os dados em função da variabilidade que o conjunto lítico apresenta entre as duas sondagens objeto de estudo (ver abaixo), e procura-se determinar o modo de exploração dos núcleos para lâminas e lamelas, as técnicas utilizadas na debitagem destes produtos e os seus padrões morfométricos, a fim de determinar variações tecnológicas e dimensionais. Uma interpretação com propósitos comparativos - isto é, visando a integração deste sítio no contexto geral das produções lâmino-lamelares neolíticas da região estremenha - é avançada nos capítulos conclusivos.

\section{O sítio do Meu Jardim}

\subsection{Localização e trabalhos arqueológicos realizados}

Pertencente ao município da Nazaré (distrito de Leiria), o concheiro do Meu Jardim encontra-se na margem norte do paleoestuário da Lagoa da Pederneira, hoje transformada numa planície aluvial, a 1,5 km da atual linha de costa, numa altitude compreendida entre 9 e 19 metros a.n.m. (Figure 1). Este paleoestuário é parte integrante do diápiro das Caldas da Rainha, resultando da erosão quaternária do seu núcleo (constituído por margas), processo que originou várias depressões inundadas pela transgressão flandriana através de entalhes no bordo ocidental do diápiro, que o separa do Oceano Atlântico. Desta dinâmica resultou a formação dos ambientes lagunares de Óbidos, Alfeizerão, São Martinho do Porto e Pederneira. No que respeita a este último, o assoreamento que formou o paul e a várzea atuais ter-se-á iniciado após a desaceleração da subida do nível do mar, cerca de 3800 a.n.e., e que se estabilizou por volta de 1800 a.n.e. (Dinis et al. 2005; Henriques \& Dinis 2005). 


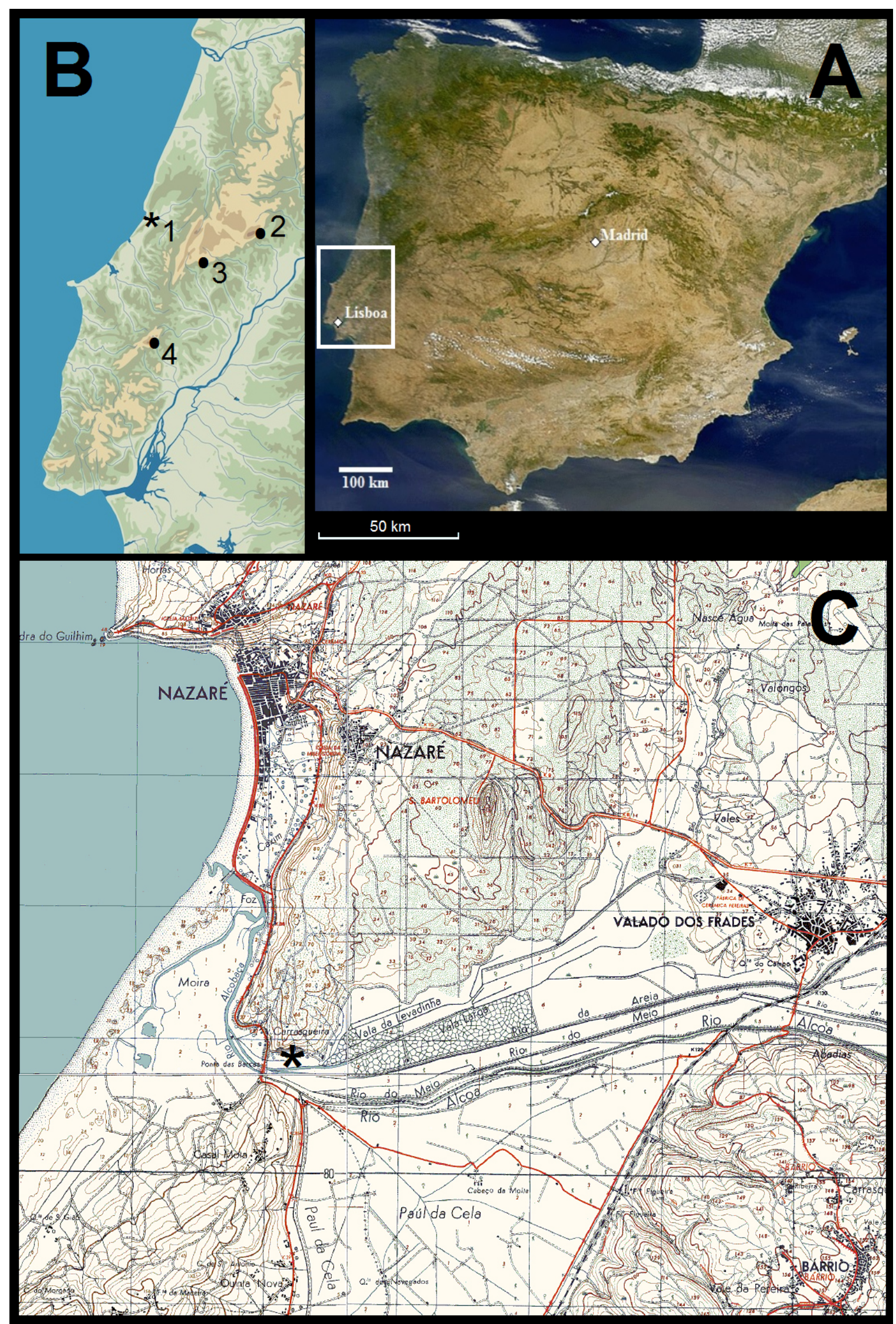

Figura 1. Localização do concheiro do Meu Jardim (asterisco). Sítios no mapa B. 1: Meu Jardim; 2: Cerradinho do Ginete (Torres Novas); 3: Gruta do Lugar do Canto (Alcanena); 4: Algar do Bom Santo (Alenquer).

Figure1. Location of the Meu Jardim shell-midden (asterisk). Sites in map B. 1: Meu Jardim; 2: Cerradinho do Ginete (Torres Novas); 3: Gruta do Lugar do Canto (Alcanena); 4: Algar do Bom Santo (Alenquer). 
O concheiro pré-histórico formou-se numa plataforma aplanada da margem direita do paleoestuário, na extremidade interior do canal que o ligava ao oceano, num ambiente dunar (Figure 2). Tratar-se-ia, à época da ocupação pré-histórica, de uma área de clara influência marítima, estando então o nível do mar entre 3 a 5 metros mais baixo que o atual (Dinis et al. 2005; Henriques \& Dinis 2005). Este posicionamento permitia então um acesso quase imediato a diferentes áreas de recursos, nomeadamente lagunares, marinhos e - o que é importante para o presente estudo - a jazidas de sílex existentes mais a norte, nas formações calcárias do Jurássico Superior, cuja exploração está na origem do topónimo Pederneira atribuído à lagoa e à povoação aí existente.

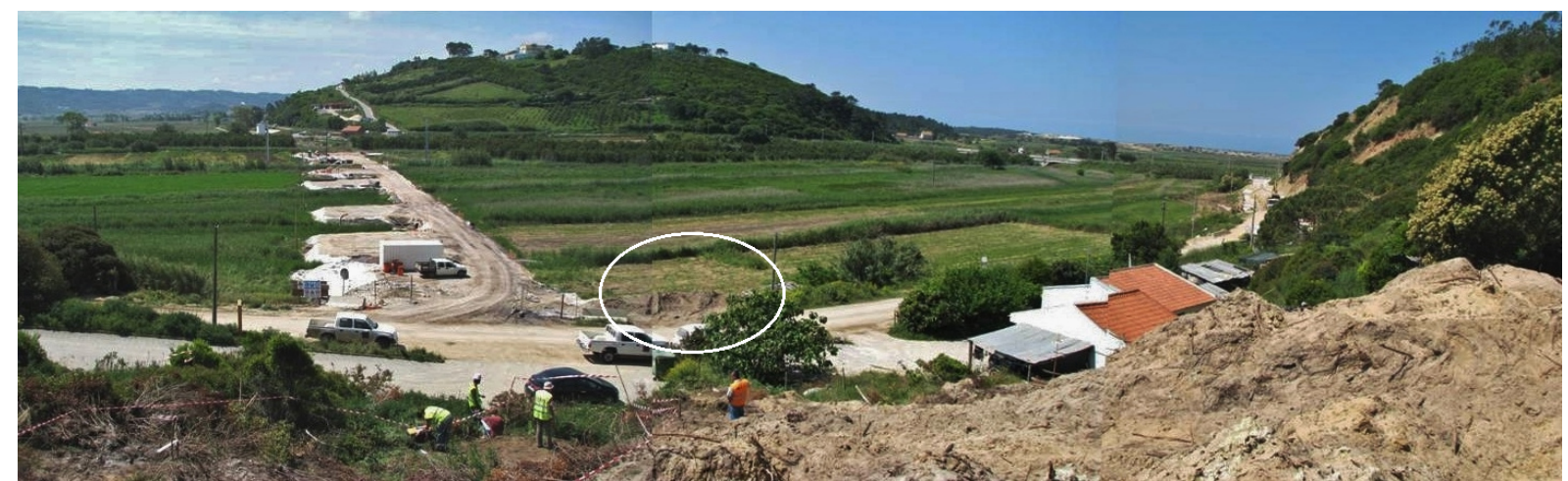

Figura 2. Vista dos trabalhos no Meu Jardim, com a Lagoa da Pederneira no lado esquerdo da imagem. O círculo branco indica a área das sondagens arqueológicas.

Figure 2. Overview of the works at Meu Jardim, with the Pederneira Lagoon on the left of the photo. White circle indicates the archaeological intervention area.

A identificação e escavação do concheiro do Meu Jardim teve lugar no âmbito do acompanhamento arqueológico decorrente da construção de um viaduto da variante da Estrada Nacional 242 que atravessa a atual várzea do Rio Alcoa, tendo os trabalhos sido realizados pela empresa ERA Arqueologia S.A. (Valera \& Santos 2010). À data de início dos trabalhos, o sítio encontrava-se já parcialmente afetado pela construção do pátio e acessos ao Restaurante Meu Jardim (do qual tomou o nome), sendo então possível observar alguns níveis conquíferos nos taludes em frente do mesmo, virados para a lagoa. As escavações incidiram no troço terminal norte do tabuleiro do viaduto (Figure 2), onde foram abertas as Sondagens 2 e 3, e na área de um dos últimos pilares norte, onde se abriu a Sondagem 1 (Figure 3). No total, foram escavados $102 \mathrm{~m}^{2}$.

\subsection{Estratigrafia e ocupações humanas}

Apesar dos seus $10 \mathrm{~m}^{2}$ de área, a Sondagem 2 - implantada na extremidade oeste da área de dispersão de materiais na plataforma imediatamente acima da Sondagem 1, a uma cota de 16,5 metros a.n.m. - caracteriza-se pela quase inexistência de restos de talhe da pedra, razão pela qual não foi incluída no presente estudo. Deste modo, apenas as Sondagens 1 e 3 serão objeto de descrição e análise (Figure 3).

As complexas sequências estratigráficas registadas em cada uma daquelas sondagens permitem o estabelecimento de fases de ocupação distintas, que devem ser tidas em conta para um entendimento pormenorizado da sucessão das presenças humanas neste local, assim como da sua funcionalidade específica e do contexto cultural mais amplo em que se integram. $\mathrm{O}$ estudo da componente de pedra lascada - como, aliás, de qualquer outra manifestação arqueológica do Meu Jardim - deve, portanto, obedecer a esse faseamento e não ser tomada na sua totalidade como uma unidade coerente de análise. Assim, propõe-se abaixo um faseamento próprio para cada sondagem, ora baseado na existência de unidades estratigráficas 
(UEs) estéreis arqueologicamente (correspondentes a hiatos na ocupação humana), no caso da Sondagem 1, ou na alternância entre níveis coluvionares e níveis conquíferos, no caso da Sondagem 3. Porém, dois fatores impedem para já que se proceda a esta análise fina da sequência ocupacional: 1) o faseamento que se apresenta é provisório e deverá ser confirmado no futuro com base num quadro geral da variabilidade estilística e tecnológica das produções cerâmicas e, de preferência, também através da sua datação sistemática por radiocarbono; 2) o reduzido número de peças em determinadas UEs e fases de ocupação impede a obtenção de conclusões assentes em amostras quantitativamente representativas.
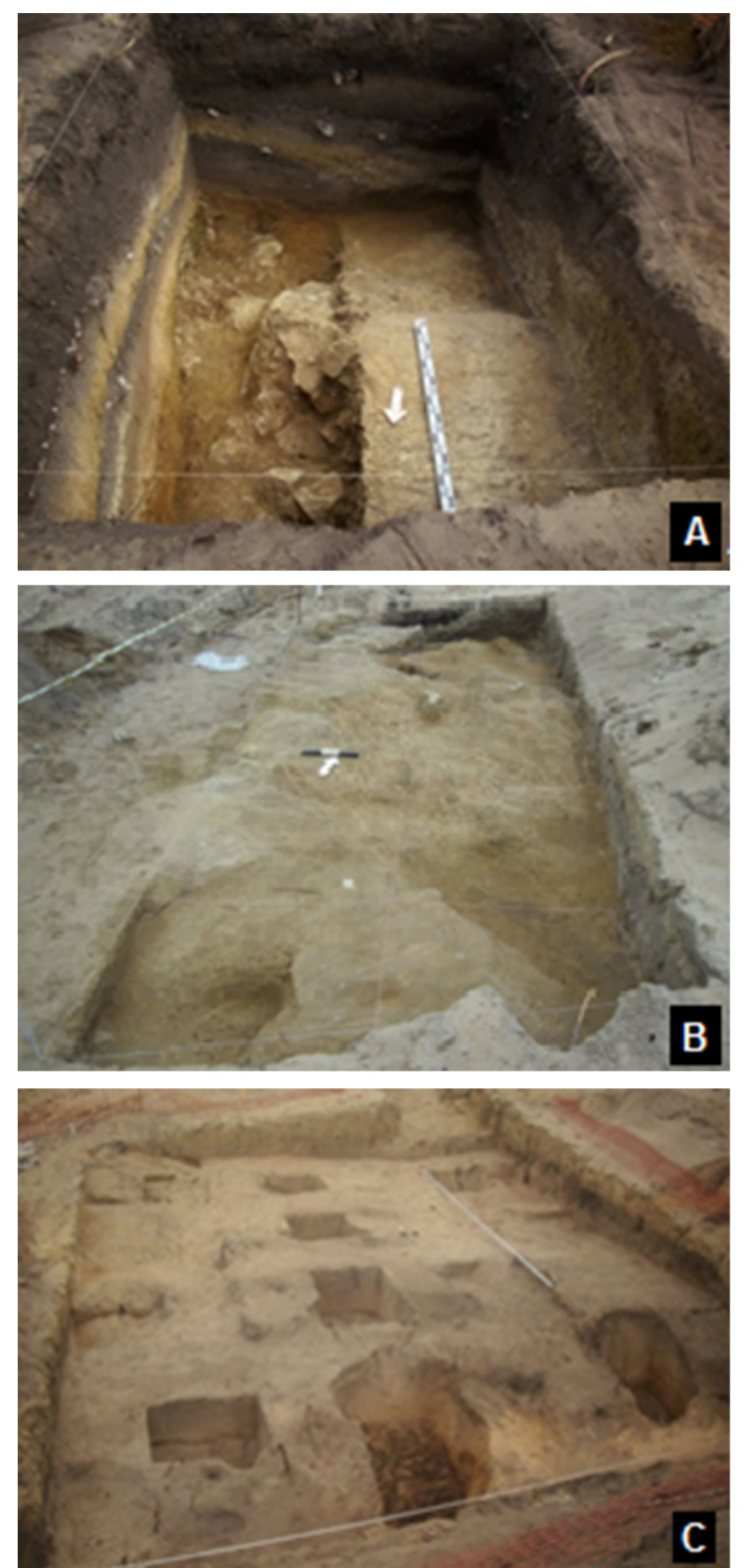

Figura 3. Planta geral (direita) e planos finais (esquerda) das sondagens realizadas no concheiro do Meu Jardim, com indicação dos perfis estratigráficos das Sondagens 1 e 3 (ver Figure 4). A: Sondagem 1; B: Sondagem 2; C: Sondagem 3.

Figure 3. General plan (right) and final plans (left) of the tests excavated at the shell-midden of Meu Jardim, with location of the stratigraphic profiles of Tests 1 and 3 (see Figure 4). A: Test 1; B: Test 2; C: Test 3. 


\subsubsection{Sondagem 1}

Com uma área de $6 \mathrm{~m}^{2}$, esta sondagem está entre os 9 e 11 metros a.n.m., já no declive a sul da plataforma onde se localiza a área aparentemente nuclear do concheiro (Figure 3). A sequência estratigráfica registrada, que atingiu $2,5 \mathrm{~m}$ de profundidade, revelou ocupações humanas formadas por densas acumulações de conchas intercaladas por momentos de sedimentação coluvionar arqueologicamente estéreis (argilas amareladas embalando margas e calcários) relacionados com a evolução da vertente (Figure 4). Documentam, assim, uma intermitência na ocupação desta área do concheiro, marginal ao seu ponto central.

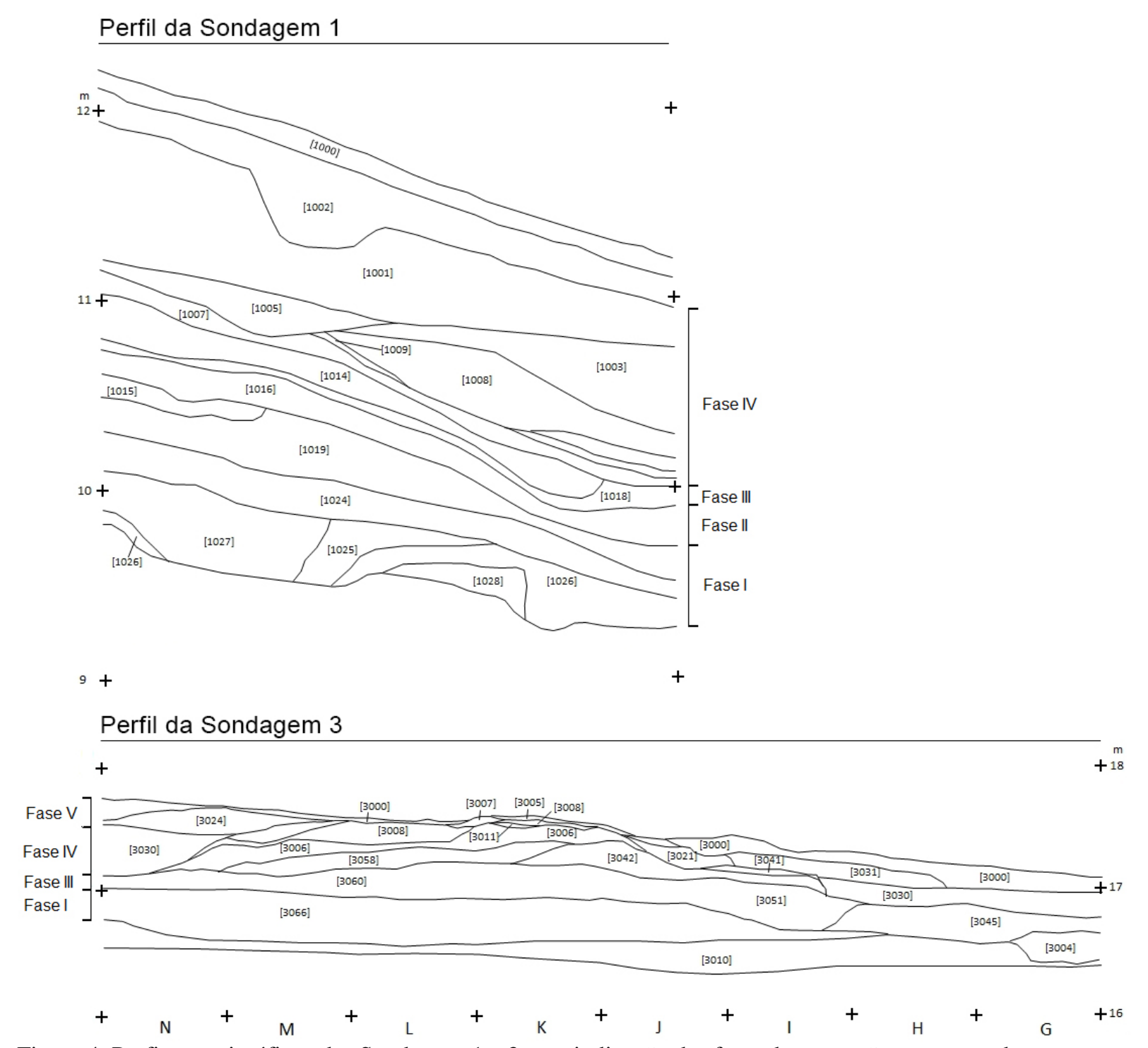

Figura 4. Perfis estratigráficos das Sondagens 1 e 3 com indicação das fases de ocupação representadas.

Figure 4. Stratigraphic profiles of Tests 1 and 3 with indication of the represented occupation phases.

A base da estratigrafia era composta por depósitos coluvionares arqueologicamente estéreis (UEs 1024, 1025, 1026 e 1028). Sobre estes registou-se um paleossolo (UE 1019) e dois depósitos (UEs 1020 e 1023) que correspondem ao momento mais antigo de ocupação desta área do concheiro (Fase I). Seguiu-se um curto episódio de abandono representado pelo depósito coluvionar UE 1015, após o qual se registou um segundo momento de ocupação (Fase II), consubstanciado no depósito UE 1016. Seguiu-se nova interrupção, agora aparentemente mais longa e dando origem à acumulação de sete depósitos de origem 
coluvionar (UEs 1018, 1014, 1017, 1013, 1012, 1022, 1004), sobre os quais ocorreria uma nova ocupação mais prolongada e intensa (Fase III) materializada num complexo estratigráfico composto por um paleossolo (UE 1007), vários depósitos conquíferos (UEs 1009, 1008, 1006 e 1005), uma possível estrutura de combustão (UE 1021), um aglomerado de grandes blocos de sílex (UE 1022) e vários outros depósitos coluvionares (UEs 1011, 1010 1003, 1001). A sequência termina com dois espessos depósitos com muitas raízes (e escassos materiais arqueológicos) correspondentes a processos de formação de solos recentes.

Os materiais desta sondagem revelam uma preponderância do talhe da pedra, mas ocorre também cerâmica (com fraturas pouco erodidas) e fauna malacológica (abundante), mamalógica e ictiológica.

\subsubsection{Sondagem 3}

A sondagem 3, com uma área total de $86 \mathrm{~m}^{2}$, foi implantada na mesma plataforma, a Este da Sondagem 2 (Figure 3), numa área onde se observara uma grande acumulação de conchas associadas a alguns materiais líticos e cerâmicos (Figure 4).

A base da estratigrafia era, uma vez mais, constituída por depósitos coluvionares praticamente estéreis do ponto de vista arqueológico, com uma potência conjunta de cerca de $1 \mathrm{~m}$, assentando diretamente no substrato, que se apresenta irregular e com uma ligeira pendente NE-SO. As evidências da primeira ocupação (Fase I) correspondem a uma estrutura pétrea subcircular com alguns termoclastos (UE 3068) e a um depósito conquífero (UE 3066). Estas evidências estavam cobertas pelos depósitos UEs 3072 e 3004, o último dos quais integrava, a cotas distintas, cinco estruturas de combustão ovaladas ou circulares (UEs 3020, 2026, 3044, 3046 e 3062), com sedimentos rubefactos e termoclastos (Fase II). Seguia-se uma sequência de depósitos conquíferos (Fase III), tendo sido possível distinguir camadas compostas por diferentes espécies malacológicas (UEs, 3051=3060, 3042, 3058=3069, 3006 $=3022=3041,3011,3052,3008=3015=3018=3053)$ e uma área de restos de talhe in situ (UE 3070). Sobre estes níveis conquíferos registaram-se dois depósitos sedimentares enegrecidos com fragmentos cerâmicos em conexão (UEs 3047 e 3050), aos quais se sobrepõe novo nível conquífero, agora com menor densidade de conchas (UE 3019=3030), formando no seu conjunto a Fase IV. A estratigrafia culmina numa série de depósitos arenosos onde por vezes se registavam algumas concentrações de conchas (UEs 3005, 3013, 3016), correspondendo à última fase atestada de ocupação pré-histórica nesta sondagem (Fase V).

Estamos, assim, perante uma área de sucessivas acumulações de restos de consumo de moluscos (assim como de alguma fauna mamalógica) e que se desenvolve pela vertente, estando delimitada a norte por um espaço de ocupação com estruturas de combustão, ao que tudo indica, a área nuclear do sítio do Meu Jardim.

\subsubsection{Componente material e cronologia das ocupações}

Para além da abundante indústria em pedra lascada, objeto do presente estudo, o sítio do Meu Jardim forneceu também bastante cerâmica, sempre muito fragmentada. A sua decoração inclui impressões e incisões, frequentemente conjugadas. As organizações decorativas reconstituídas apresentam bandas de linhas de puncionamentos, triângulos incisos, ziguezagues verticais (espinhados), barras diagonais incisas preenchidas por impressões perpendiculares, e bordos denteados. Estão também presentes elementos de preensão, nomeadamente pegas cónicas com ou sem perfuração, pegas horizontais ou asas de fita. Tratase, em suma, de produções cerâmicas características do Neolítico antigo (Valera \& Santos 2010), mas ocasionalmente também existentes no Neolítico médio regional (por exemplo, 
Carvalho 1998b). A pedra polida está totalmente ausente e os elementos de moagem, estando presentes, são relativamente raros e correspondem essencialmente a moventes.

Relativamente aos dados faunísticos, pode avançar-se de forma preliminar (Valera \& Santos 2010) que a fauna malacológica é dominada pela ostra (Ostrea edulis) e pelo berbigão (Cerastoderma edulis), aparecendo com menor representatividade a amêijoa (Venerupis decussata) e, com carácter vestigial, o búzio (Littorina littorea), a lapa (Patella sp.) e o mexilhão (Mytilus sp.), revelando portanto uma exploração preponderante dos ambientes arenovasosos estuarinos a par da vizinha faixa costeira rochosa (Figure 1). A pesca está igualmente atestada pela presença de restos de Sparidae (pargo, dourada e possivelmente tainha). A fauna mamalógica ocorre de forma pontual, registando-se a presença de boi (Bos taurus), suínos (Sus sp.), ovinos/caprinos (Ovis aries, Capra hircus) e coelho (Oryctolagus cuniculus), o que, apesar da escassez de restos, documenta ainda assim um espectro económico mais amplo que a estrita especialização no marisqueio e na pesca.

Para a aferição da cronologia do sítio foi realizada até ao momento uma datação de radiocarbono sobre uma amostra de conchas de berbigão (inédita) proveniente da UE 3052 da Sondagem 3 (não representada no perfil estratigráfico da Figure 4), isto é, pertencente à Fase III. O resultado obtido apresenta um intervalo que abrange o final do $\mathrm{V}$ e o início do IV milénio a.n.e., ou seja, o Neolítico médio inicial.

\section{Análise lítica}

\subsection{Inventário}

O conjunto de materiais de pedra lascada do Meu Jardim é composto, no total, por 639 artefactos (Tables 1 and 2), provenientes de matérias-primas disponíveis localmente (sílex, quartzito e quartzo), que se distribuem pelo seguinte inventário global: 24 núcleos, 572 produtos debitados (487 lascas, 66 lamelas e 19 lâminas), uma peça de reavivamento ou preparação de núcleo ou ambos, 245 resíduos (166 esquírolas, 78 fragmentos inclassificáveis e um microburil), 37 utensílios retocados e duas peças com sinais de uso. Para além destas peças com talhe intencional, foram também registados outros 747 elementos líticos: cinco seixos em bruto, dois percutores, quatro fragmentos de bigornas e 736 termoclastos. Ainda que não tenham sido analisados, estes foram contabilizados por matéria-prima e distribuídos no inventário conforme a sua tipologia.

\subsection{Análise da produção lâmino-lamelar}

A componente lâmino-lamelar do talhe do sílex no Meu Jardim é tratada e discutida de forma conjunta. Porém, na fase de inventário, procedeu-se à distinção entre ambas as categorias morfológicas, em que os módulos até $1,2 \mathrm{~cm}$ de largura se classificam como lamelas, e os que apresentam larguras superiores àquele valor se consideram lâminas, independentemente do respetivo comprimento.

\subsubsection{Sondagem 1}

O conjunto de produtos alongados (em bruto) e núcleos da Sondagem 1 é composto por dois tipos de matérias-primas de obtenção local (Table 1): sílex (quatro núcleos e 14 produtos alongados) e quartzo (um núcleo e dois produtos alongados). O sílex surge em tons de creme, amarelados, acastanhados e acinzentados. 
Tabela 1. Inventário do conjunto de pedra lascada da Sondagem 1, por matéria-prima (S - sílex; Qt - quartzito; Qz - quartzo; O - outros).

Table 1. Inventory of the knapped stone assemblage from Test 1, by raw material (S - flint; Qt - quartzite; Qz quartz; O - others).

\begin{tabular}{|c|c|c|c|c|c|c|c|c|c|}
\hline & \multicolumn{4}{|c|}{ Fase I } & \multirow{2}{*}{$\begin{array}{c}\text { Fase II } \\
\mathrm{S}\end{array}$} & \multicolumn{4}{|c|}{ Fase III } \\
\hline & $\mathrm{S}$ & Qt & Qz & $\mathrm{O}$ & & $\mathrm{S}$ & Qt & Qz & $\mathrm{O}$ \\
\hline \multicolumn{10}{|l|}{ Material de debitagem: } \\
\hline Lascas corticais & 2 & & & & & 6 & & 1 & \\
\hline Lascas parcialmente corticais & & 1 & & & & 8 & & 1 & \\
\hline Lascas não corticais & 4 & 4 & & & 2 & 22 & & 1 & \\
\hline Lâminas & & & & & & 3 & & 1 & \\
\hline Lamelas & 1 & & & & & 10 & & 1 & \\
\hline Núcleos & & & & & & 4 & & 1 & \\
\hline \multicolumn{10}{|l|}{ Resíduos: } \\
\hline Esquírolas & 1 & & 1 & & 1 & 5 & & 2 & \\
\hline Fragmentos & 2 & & 1 & & & 7 & 1 & 1 & \\
\hline Utensílios retocados & & & & & & 7 & & & \\
\hline \multicolumn{10}{|l|}{ Diversos: } \\
\hline Termoclastos & & 3 & & 2 & & 1 & 36 & 4 & 5 \\
\hline Total & 10 & 8 & 2 & 2 & 3 & 73 & 37 & 13 & 5 \\
\hline
\end{tabular}

Tabela 2. Inventário do conjunto de pedra lascada da Sondagem 3, por matéria-prima (S - sílex; Qt - quartzito; Qz - quartzo; O - outros).

Table 2. Inventory of the knapped stone assemblage from Test 3, by raw material (S - flint; Qt - quartzite; Qz quartz; O - others).

\begin{tabular}{|c|c|c|c|c|c|c|c|c|c|c|c|c|c|c|c|c|}
\hline & \multicolumn{4}{|c|}{ Fase I } & \multicolumn{4}{|c|}{ Fase II } & \multicolumn{4}{|c|}{ Fase III } & \multicolumn{4}{|c|}{ Fase IV } \\
\hline & $\mathrm{S}$ & Qt & Qz & 0 & $S$ & Qt & Qz & $\mathrm{O}$ & $\mathrm{S}$ & Qt & Qz & $\mathrm{O}$ & $\mathrm{S}$ & Qt & Qz & $\mathrm{O}$ \\
\hline \multicolumn{17}{|c|}{ Material de debitagem: } \\
\hline Lascas corticais & & & & & 19 & 4 & & & 6 & & 5 & & 2 & 1 & 1 & \\
\hline $\begin{array}{l}\text { Lascas parcialmente } \\
\text { corticais }\end{array}$ & 4 & 3 & & & 57 & 4 & 2 & & 14 & 1 & 16 & & 12 & 1 & & \\
\hline Lascas não corticais & 7 & & & & 173 & 16 & 29 & & 15 & & 28 & & 13 & & 2 & \\
\hline Lâminas & & & & & 11 & & 2 & & 1 & & 1 & & & & & \\
\hline Lamelas & 1 & & & & 33 & & 13 & & 2 & & 1 & & 4 & & & \\
\hline Núcleos & 2 & & 1 & & 8 & & 3 & & 3 & & & & 2 & & & \\
\hline $\begin{array}{l}\text { Material de } \\
\text { reavivamento }\end{array}$ & & & & & & & & & & & & & 1 & & & \\
\hline \multicolumn{17}{|l|}{ Resíduos: } \\
\hline Esquírolas & 1 & 3 & & & 66 & 12 & 19 & & 8 & & 36 & & 9 & & 2 & \\
\hline Fragmentos & & & & & 35 & & 1 & & 16 & & 3 & & 9 & & 2 & \\
\hline Microburil & & & & & 1 & & & & & & & & & & & \\
\hline \multicolumn{17}{|l|}{ Utensilagens: } \\
\hline Sinais de uso & & & & & 1 & & & & 1 & & & & & & & \\
\hline Retoque & & & & & 25 & & & & 3 & & & & 2 & & & \\
\hline \multicolumn{17}{|l|}{ Diversos: } \\
\hline Seixos brutos & & & & & & 3 & 1 & & & 1 & & & & & & \\
\hline Percutores & & & & & & 2 & & & & & & & & & & \\
\hline Bigornas & & & & & & & & 3 & & 1 & & & & & & \\
\hline Termoclastos & & 7 & 1 & 16 & 17 & 388 & 38 & 88 & 4 & 40 & 2 & 29 & 2 & 35 & 3 & 15 \\
\hline Total & 15 & 13 & 2 & 16 & 446 & 428 & 109 & 91 & 73 & 43 & 92 & 29 & 56 & 37 & 7 & 15 \\
\hline
\end{tabular}


Dois núcleos prismáticos em sílex (um dos quais ainda com vestígios de córtex) e um em quartzo foram usados na debitagem de produtos alongados. Os primeiros apresentam, respetivamente, 3,45 e 3,71 cm de comprimento, 2,77 e 3,18 cm de largura e 2,09 e 2,38 cm de espessura. O núcleo em quartzo, por seu lado, tem 2,85 cm de comprimento, 3,4 cm de largura e $1,77 \mathrm{~cm}$ de espessura. A preparação das plataformas dos núcleos em sílex resume-se à facetagem, sem regularização da cornija. Por seu lado, o núcleo de quartzo tem uma plataforma lisa e apresenta regularização da cornija. Não foram registados materiais de preparação ou reavivamento, ou ambos.

No conjunto de produtos alongados em sílex desta sondagem predominam as lamelas em bruto, com uma percentagem de fragmentação elevada ( $n=9 ; 69 \%)$, o que limita as deduções quanto à morfologia geral das peças. A maioria não apresenta vestígios de córtex. No geral, foram fraturadas acidentalmente $(n=4 ; 40 \%)$ ou por flexão $(n=2 ; 20 \%)$. A secção transversal trapezoidal é predominante no grupo lamelar ( $n=5 ; 50 \%)$, sendo a triangular no grupo laminar $(n=2 ; 67 \%)$. No que respeita à forma e perfil, apenas foi possível analisar estas categorias nos produtos lamelares, onde prevalecem os bordos paralelos $(n=5 ; 50 \%)$, os perfis direitos $(n=2$; $50 \%$ ) ou com acidentes de ultrapassagem $(n=2 ; 50 \%)$. Nos atributos específicos (Table 3), dominam perfis proximais direitos, talões lisos ou em diedro, bolbos nítidos sem ondulações, e nervuras regulares paralelas, como se pode observar nos exemplares n. ${ }^{\circ} 1$ e 2 da Figure 5. No grupo laminar existe apenas uma peça com talão linear e bolbo reduzido e com ondulações. No geral, o tratamento térmico é muito frequente ( $\mathrm{n}=11 ; 79 \%)$.

Tabela 3. Atributos específicos do talhe lâmino-lamelar em sílex da Sondagem 1. (a) Peças inteiras e proximais. (b) Peças inteiras e fraturadas. (c) Apenas peças em sílex.

Table 3. Specific attributes of the blade or bladelet knapping in flint from Test 1. (a) Complete and proximal artifacts. (b) complete and broken artifacts. (c) Only flint artifacts.

\begin{tabular}{ll|cc|cc}
\hline & & \multicolumn{2}{|c|}{ Lâminas } & \multicolumn{2}{c}{ Lamelas } \\
& & $\%$ & $\mathrm{~N}$ & $\%$ & $\mathrm{~N}$ \\
\hline Bolbo (a) & Nítido & & & $100 \%$ & 8 \\
& Reduzido & $100 \%$ & 1 & & \\
Ondulações (a) & Presentes & $100 \%$ & 1 & $13 \%$ & 1 \\
& Ausentes & & & $86 \%$ & 7 \\
Nervuras regulares (b) & Presentes & $33 \%$ & 1 & $73 \%$ & 8 \\
& Ausentes & $67 \%$ & 2 & $27 \%$ & 3 \\
Tratamento térmico (c) & Presente & $100 \%$ & 3 & $73 \%$ & 8 \\
& Ausente & & & $27 \%$ & 3 \\
Perfil proximal (a) & Direito & $100 \%$ & 1 & $75 \%$ & 6 \\
& Côncavo & & & $25 \%$ & 2 \\
Talão (a) & Liso & & & $50 \%$ & 4 \\
& Diedro & & & $38 \%$ & 3 \\
& Linear & $100 \%$ & 1 & & \\
& Esmagado & & & $13 \%$ & 1 \\
\hline
\end{tabular}

No que respeita aos padrões métricos, as larguras variam nos $0,5-1,39 \mathrm{~cm}$, predominando portanto as peças de pequenas dimensões, o que é confirmado pelos comprimentos observáveis nas peças inteiras (1,83-4,77 cm) e nas respetivas espessuras $(0,13-0,66 \mathrm{~cm})$.

A partir da análise dos atributos morfológicos, colocamos a hipótese de se ter recorrido ao "método prismático" na exploração dos núcleos (sensu Carvalho 1998a), e ao predomínio da técnica de debitagem por pressão, se se atentar aos padrões específicos observáveis no talhe lâmino-laminar (Table 3), acima descritos. A frequência elevada de bolbos nítidos, usualmente tidos como característicos do talhe por percussão indireta, não deve ser valorizada se se considerarem as reduzidas dimensões gerais das peças. 

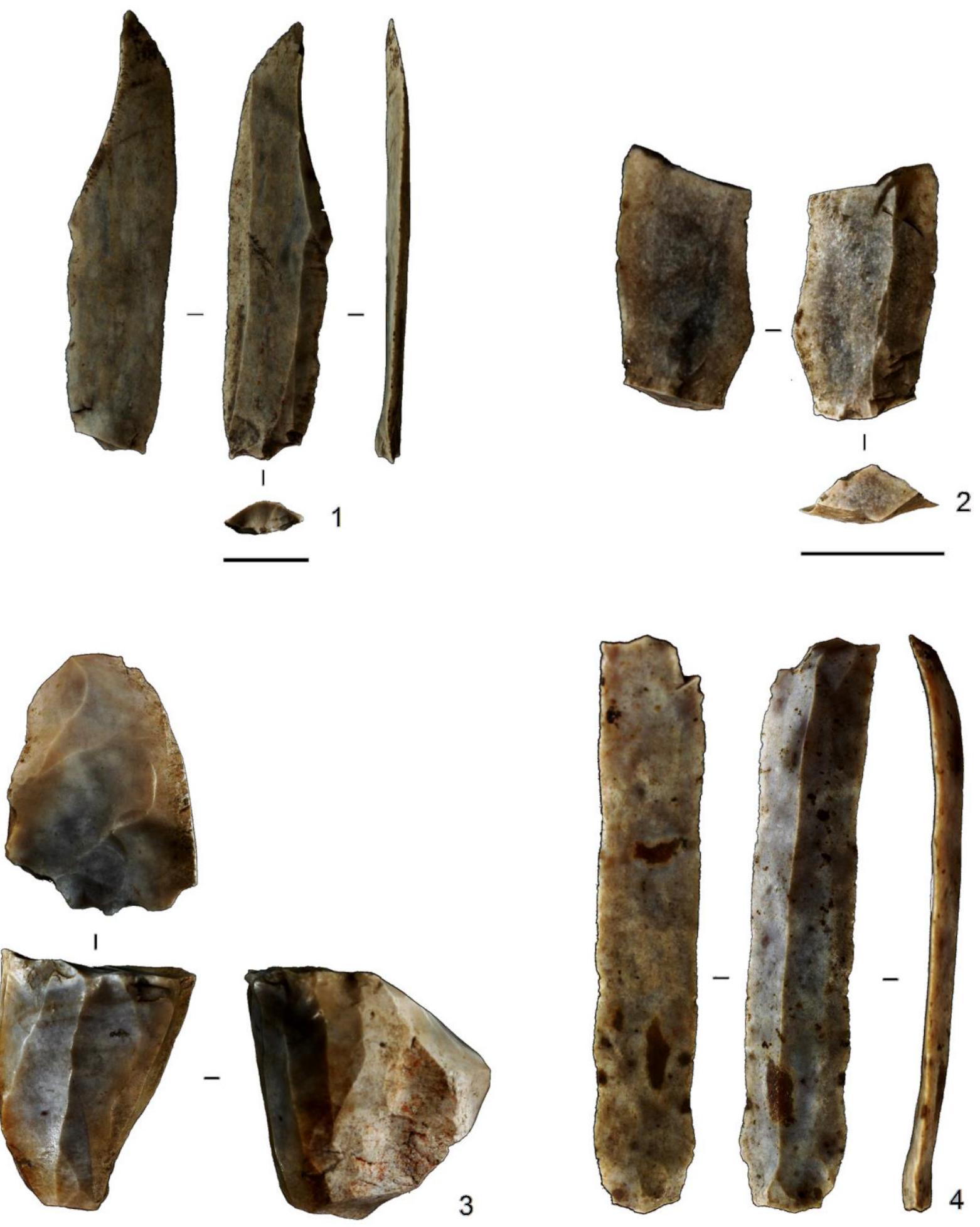

Figura 5. Exemplos de núcleo e lamelas do Meu Jardim. 1. 1: lamela inteira com talão diedro (Sondagem 1, Fase III); 2: lamela de fratura proximal com talão liso (Sondagem 1, Fase III); 3: núcleo prismático para lamelas com plataforma facetada (Sondagem 3, UE 3030, Fase IV); 4: lamela inteira, não retocada, de talão liso (Sondagem 3, Fase II). (barras $=1 \mathrm{~cm})$.

Figure 5. Examples of core and bladelets from Meu Jardim: 1: complete bladelet with dihedral butt (Test 1, Phase III); 2: proximal bladelet with flat butt (Test 1, Phase III); 3: prismatic core for bladelet production, with facetted platform (Test 3, Phase IV); 4: complete bladelet, unretouched, with flat butt (Test 3, Phase II). (bars = $1 \mathrm{~cm})$. 


\subsubsection{Sondagem 3}

O conjunto de produtos alongados (em bruto ou transformados em utensílios) e núcleos da Sondagem 3 (Table 2) é formado por sílex (15 núcleos, 81 produtos alongados, 29 dos quais retocados) e quartzo (quatro núcleos e 17 lâminas e lamelas), sendo novamente o primeiro a matéria-prima predominante, à semelhança do verificado na Sondagem 1. No que diz respeito aos tipos cromáticos do sílex, mantêm-se os mesmos tons observados anteriormente, o que indica a exploração das mesmas jazidas.

Da Sondagem 3 foram recuperados quatro núcleos prismáticos em sílex (com comprimentos entre 3,01 e 5,38 cm, larguras entre 1,99 e 3,84 cm e espessuras entre 1,39 e $3,59 \mathrm{~cm}$ ) e dois em quartzo (com comprimentos entre 2,19 e 2,73 cm, larguras entre 1,64 e $2,35 \mathrm{~cm}$ e espessuras entre 1,56 e 2,32 cm), predominando em ambas as rochas as peças com vestígios de córtex ( $\mathrm{n}=5 ; 83 \%)$. As plataformas destes núcleos são facetadas (três em sílex e um em quartzo), havendo apenas dois com plataformas lisas (um em cada rocha). Em nenhum dos casos se verificou regularização da cornija. Contudo, uma peça integrável na categoria de material de manutenção de núcleos consiste precisamente numa cornija (Table 2). Quatro dos seis núcleos prismáticos desta sondagem apresenta apenas uma plataforma e, com exceção de um exemplar, todos têm negativos de extração de lamelas (por exemplo, o núcleo com o n. ${ }^{\circ} 3$ da Figure 5) (for exemple, n. ${ }^{\circ} 3$ of Figure 5).

Os produtos alongados em sílex apresentam um índice de fragmentação igual a 85\% ( $n=69)$, destacando-se a fracturação acidental com $52 \%(n=27)$. Porém, porque se trata de um conjunto mais numeroso que o recuperado na Sondagem 1, e porque entre as peças fragmentadas predominam as extremidades proximais $(n=23 ; 44 \%)$, será possível retirar ilações melhor fundamentadas e, portanto, mais representativas no que respeita à morfologia geral da coleção (Table 4) e às técnicas empregues na sua produção (Table 5).

Tabela 4. Atributos gerais do talhe lâmino-lamelar em sílex da Sondagem 3. (a) Peças inteiras e fraturadas. (b) Apenas peças inteiras. (c) Peças inteiras e mesiais

Table 4. General attributes of the blade or bladelet knapping in flint from Test 3. (a) Complete and broken artifacts. (b) Only Complete artifacts. (c) Complete and mesial artifacts.

\begin{tabular}{llcccc}
\hline & & Lâminas & \multicolumn{2}{c}{ Lamelas } \\
& & $\%$ & $\mathbf{N}$ & $\%$ & $\mathbf{N}$ \\
\hline Secção (a) & Trapezoidal & $8 \%$ & 1 & $25 \%$ & 10 \\
& Triangular & $75 \%$ & 9 & $68 \%$ & 27 \\
& Irregular & $16 \%$ & 2 & $8 \%$ & 3 \\
\hline Perfil (b) & Direito & $33 \%$ & 1 & $30 \%$ & 3 \\
& Côncavo & & & $10 \%$ & 1 \\
& Ultrapassado & $33 \%$ & 1 & $60 \%$ & 6 \\
& Torcido & $33 \%$ & 1 & & \\
\hline Forma (c) & Divergente & $33 \%$ & 1 & $11 \%$ & 1 \\
& Convergente & & & $11 \%$ & 1 \\
& Bordos paralelos & $33 \%$ & 1 & $33 \%$ & 3 \\
& Irregular & $33 \%$ & 1 & $33 \%$ & 3 \\
& Biconvexa & & & $11 \%$ & 1 \\
\hline
\end{tabular}

Assim, a secção transversal predominante em ambos os tipos de suportes é a triangular, com 36 exemplares (69\%). As formas gerais das peças repartem-se igualmente entre os bordos paralelos e os bordos irregulares. Globalmente, predominam os fenómenos de ultrapassagem, num total de sete exemplares (54\%). O tratamento térmico está presente em mais de metade dos suportes alongados ( $n=36$; 69\%). Em termos de atributos específicos 
(Table 3), prevalecem os bolbos nítidos e sem ondulações associadas. Os talões facetados predominam nas lamelas face às lâminas, onde os talões esmagados são a maioria. Nervuras regulares e paralelas destacam-se sobretudo nas lamelas. Os perfis proximais são direitos em ambos os suportes, embora haja uma percentagem significativa de suportes lamelares com perfil proximal côncavo. Relativamente aos padrões métricos, predominam as peças de pequenas dimensões. Como se pode observar na Figure 6, as larguras apresentam dois picos, respetivamente em torno dos $0,9 \mathrm{~cm}$ e dos $1,1 \mathrm{~cm}$ (de que é exemplo a lamela ilustrada sob o n. ${ }^{\circ} 4$ da Figure 5). Há, no entanto, peças que atingem cerca de 1,7 cm de largura, como é o caso da peça n. 1 da Figure 7 . Relativamente às restantes medidas, os comprimentos das peças inteiras situam-se nos 1,39-6,94 cm e as espessuras nos 0,11-0,97 cm.

Tabela 5. Atributos específicos do talhe lâmino-lamelar em sílex da Sondagem 3. (a) Peças inteiras e proximais. (b) Peças inteiras e fraturadas. (c) Apenas peças em sílex.

Table 5. Specific attributes of the blade or bladelet knapping in flint from Test 3. (a) Complete and proximal artifacts. (b) complete and broken artifacts. (c) Only flint artifacts.

\begin{tabular}{llcccc}
\hline & & \multicolumn{2}{c}{ Lâminas } & \multicolumn{2}{c}{ Lamelas } \\
& & $\%$ & $\mathrm{~N}$ & $\%$ & $\mathrm{~N}$ \\
\hline Bolbo (a) & Nítido & $43 \%$ & 3 & $39 \%$ & 13 \\
& Pouco nítido & & & $3 \%$ & 1 \\
& Reduzido & $29 \%$ & 2 & $33 \%$ & 11 \\
& Nítido com esquirolamento & & & $21 \%$ & 7 \\
& Reduzido com esquirolamento & $29 \%$ & 2 & $3 \%$ & 1 \\
\hline Ondulações (a) & Presentes & $29 \%$ & 2 & $18 \%$ & 6 \\
& Ausentes & $71 \%$ & 5 & $82 \%$ & 27 \\
\hline Nervuras regulares (b) & Presentes & $45 \%$ & 5 & $78 \%$ & 32 \\
& Ausentes & $55 \%$ & 6 & $22 \%$ & 9 \\
\hline Tratamento térmico (c) & Presente & $82 \%$ & 9 & $66 \%$ & 27 \\
& Ausente & $18 \%$ & 2 & $34 \%$ & 14 \\
\hline Perfil proximal (a) & Direito & $71 \%$ & 5 & $45 \%$ & 15 \\
& Côncavo & $14 \%$ & 1 & $36 \%$ & 12 \\
& Irregular & $14 \%$ & 1 & $18 \%$ & 6 \\
\hline Talão (a) & Cortical & $14 \%$ & 1 & & \\
& Liso & $14 \%$ & 1 & $25 \%$ & 7 \\
& Facetado & $14 \%$ & 1 & $43 \%$ & 12 \\
& Diedro & & & $38 \%$ & 3 \\
& Linear & $14 \%$ & 1 & $4 \%$ & 1 \\
& Punctiforme & $43 \%$ & 3 & $14 \%$ & 4 \\
\hline
\end{tabular}

Por seu lado, os atributos evidenciados pelos suportes alongados em quartzo distinguemse, em alguns aspetos, dos do sílex, apesar do seu número muito menor se constituir como um impedimento a comparações sistemáticas. Ainda assim, é possível referir que a tipologia de talões se distribui uniformemente pelos exemplares lisos, punctiformes e esmagados, com dois casos cada, e que apresentam secções, sobretudo, triangulares, enquanto outros atributos não revelam tendências significantes (por exemplo, ao nível das morfologia dos bolbos, das nervuras e dos perfis proximais). No quartzo predominam mais uma vez as peças de pequenas dimensões, com as larguras das lamelas variando nos $0,79-0,92 \mathrm{~cm}$ e não ultrapassando os 1,3 cm (Figure 6). 


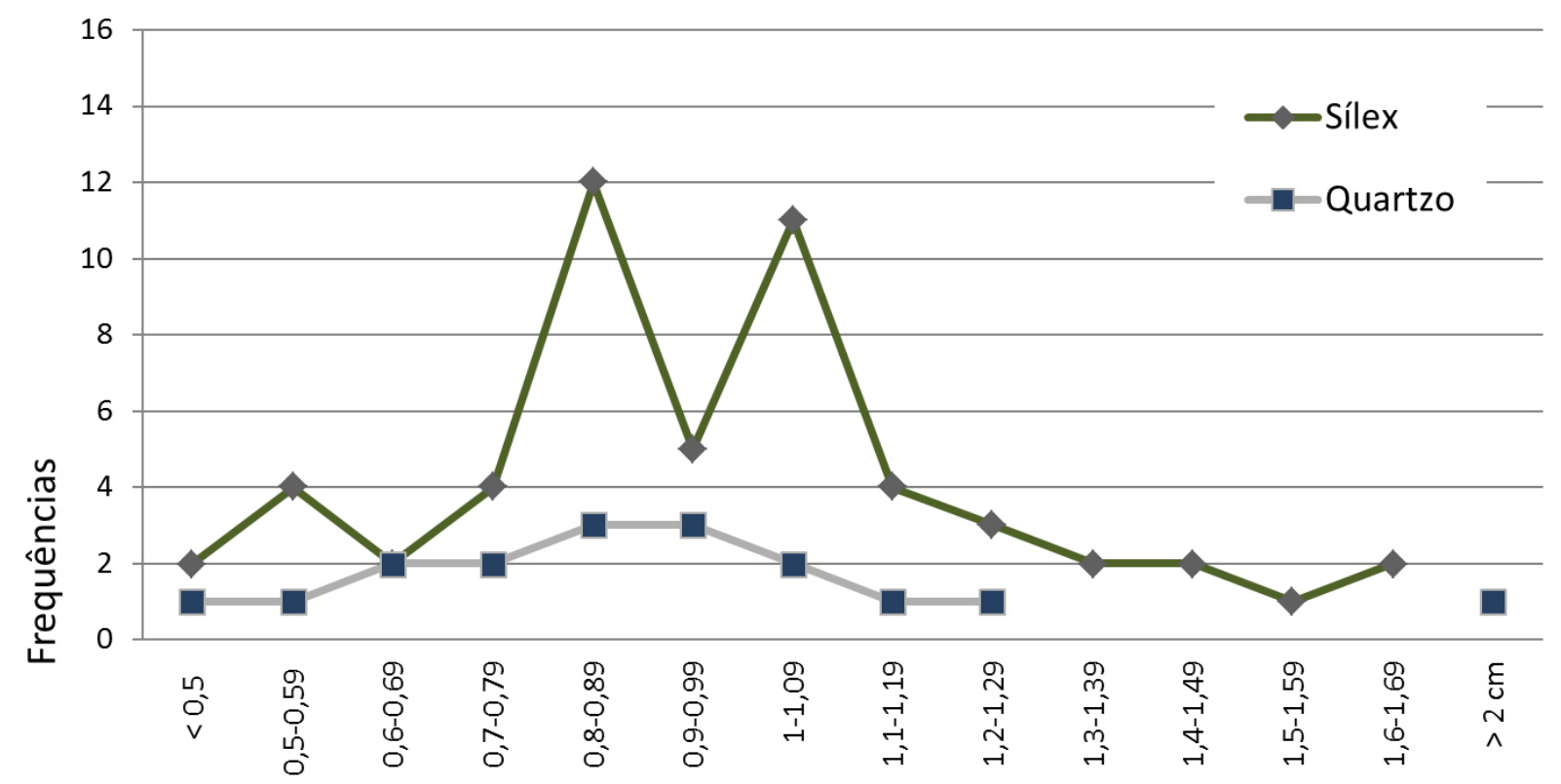

Figura 6. Variação das larguras (em $\mathrm{cm}$ ) dos produtos alongados em bruto. Figure 6. Width variation (in $\mathrm{cm}$ ) of the unretouched blades and bladelets.
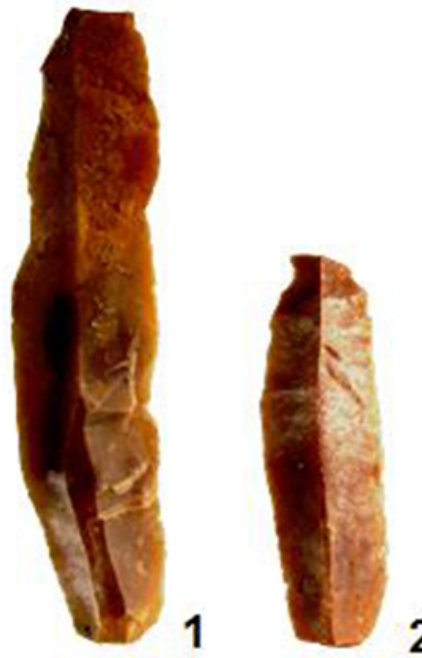

2

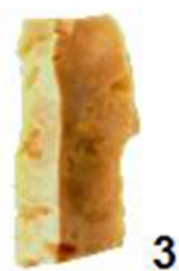

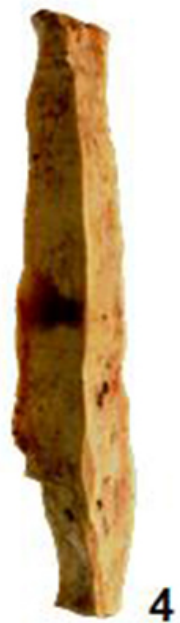

4

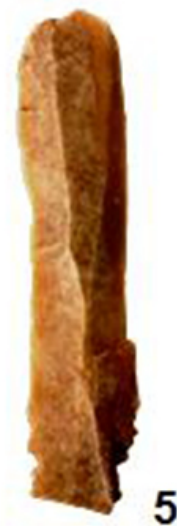

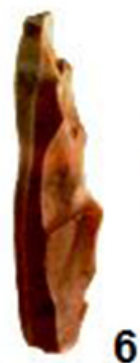

6

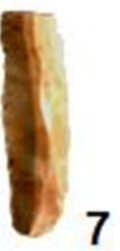

7

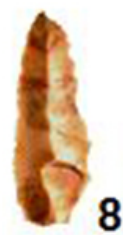

Figura 7. Lâminas e lamelas do concheiro do Meu Jardim. 1-3: lâminas da Sondagem 3, Fase III; 4-5: lamelas da Sondagem 3, Fase II; 8: lamela da Sondagem 1, Fase III; 7: lamela da Sondagem 3, Fase II; 8: lamela da Sondagem 3, Fase IV. (barra $=1 \mathrm{~cm}$ ).

Figure 7. Blades and bladelets from the shell-midden of Meu Jardim. 1-3: blades from Test 3, Phase III; 4-5: bladelets from Test 3, Phase II; 8: bladelet from Test 1, Phase III; 7: bladelet from Test 3, Phase II; 8: bladelet from Test 3, Phase IV. (bar $=1 \mathrm{~cm})$.

No que respeita às técnicas de talhe, o "método prismático" parece ter sido o escolhido para a debitagem dos produtos alongados, à semelhança do que se verificou na Sondagem 1. As técnicas de debitagem utilizadas na sua extração resultaram em peças com atributos sugestivos do recurso à técnica de debitagem por pressão (ver acima; Table 3). Os núcleos prismáticos tinham plataformas lisas ou facetadas (dois exemplares cada), sem regularização da cornija.

\subsection{Utensilagens}

Não há utensílios retocados sobre suportes lâmino-lamelares em sílex provenientes da Sondagem 1; mas, por seu lado, na Sondagem 3 encontram-se 14 utensílios sobre este tipo de 
suporte: sete lamelas com retoque marginal, uma lamela com retoque invasor unifacial, uma lâmina com entalhe, uma lâmina denticulada, uma lamela de dorso, uma truncatura sobre lâmina e dois furadores sobre lamela. Os utensílios sobre lasca (em sílex e quartzo) não serão aqui tratados. A Fase II é o momento de ocupação que detém de mais material retocado sobre suporte lâmino-lamelar ( $n=13 ; 93 \%)$, existindo também uma peça retocada na Fase III $(n=1$; $7 \%)$.

Tomadas globalmente, trata-se de peças sem córtex ( $n=13 ; 93 \%)$ e com evidência de tratamento térmico ( $\mathrm{n}=9 ; 64 \%)$. As peças fraturadas (9 exemplares) são superiores às inteiras (5 exemplares), podendo-se observar que as fraturas foram acidentais $(n=5 ; 36 \%)$ ou por flexão ( $n=3 ; 21 \%)$. À semelhança do que foi verificado nos produtos alongados em bruto da mesma sondagem, prevalecem os talões facetados nos suportes lamelares $(n=6 ; 55 \%)$ e os lisos nos laminares ( $n=4 ; 36 \%)$, em ambos os casos com bolbos nítidos $(n=7 ; 64 \%)$ e ausência de ondulações $(n=8 ; 73 \%)$. As secções triangulares $(n=7 ; 50 \%)$ associadas a nervuras regulares (n=9; 64\%) são a maioria, havendo uma representação muito elevada de peças com acidentes de ultrapassagem ( $\mathrm{n}=5 ; 60 \%)$. Em suma, parece estar presente o talhe por pressão. O tipo de retoque predominante é o direto, curto e de ângulo semi-abrupto.

No que respeita aos padrões métricos, a largura varia nos $0,6-0,99 \mathrm{~cm}$ e o comprimento entre $2,2-5,2 \mathrm{~cm}$, repetindo o padrão das peças brutas.

Relativamente às utensilagens com sinais de uso, identificaram-se duas peças em sílex com aparente vestígio de "brilho de cereal": uma lamela na Fase II de ocupação na Sondagem 3, sem córtex, reduzida à sua extremidade distal, fraturada acidentalmente, com nervuras regulares destacadas, secção triangular, e ausência de tratamento térmico; e uma lâmina inteira de perfil torcido na Fase III, parcialmente cortical, com talão esmagado, bolbo reduzido com ondulações, nervuras regulares paralelas e secção triangular. Enquanto a lamela apresenta pequenas dimensões $(0,84 \mathrm{~cm}$ de largura e $0,25 \mathrm{~cm}$ de espessura), a lâmina é uma peça mais robusta $(6,72 \mathrm{~cm}$ de comprimento, $1,51 \mathrm{~cm}$ de largura e $0,52 \mathrm{~cm}$ de espessura).

\subsection{Síntese}

O predomínio que o sílex evidencia no Meu Jardim (Tables 1 and 2) encontra explicação não só na qualidade intrínseca desta rocha para o talhe, como também, e sobretudo, pela facilidade da sua obtenção nas jazidas localizadas nas proximidades do concheiro. Embora o sílex deva ser considerado um recurso ubíquo à escala da região estremenha (por exemplo, Aubry et al. 2014), por vezes não se encontra disponível localmente. Este fator introduz alguma variabilidade nas proporções relativas entre as matérias-primas mais comummente utilizadas (sílex, quartzo e quartzito). Daí também a importância do Meu Jardim para o conhecimento das produções lâmino-laminares em sílex neste período: trata-se de um sítio em que a referida limitação não teve lugar.

Os núcleos prismáticos que integraram sequências de talhe visando a produção destes suportes alongados - isto é, o “método prismático" (ver acima) - apresentam poucos levantamentos e não foram, por regra, explorados até à sua exaustão. Este padrão de comportamento económico é indicador indireto da presença de jazidas desta rocha no território envolvente, a qual se apresenta portanto de modo relativamente abundante e de fácil aquisição. Desta forma, não haveria necessidade de explorar até ao esgotamento, reavivar ou retomar os blocos de sílex trazidos para o sítio, o que explica também a ausência de material de preparação e reavivamento de núcleos. No Meu Jardim, a debitagem dos núcleos prismáticos está pois orientada para a extração de produtos alongados, sobretudo lamelas. $\mathrm{O}$ "método prismático", aplicado essencialmente no sílex (existem três exemplares em quartzo contra seis em sílex), é a principal estratégia empregue na produção de suportes alongados, responsável pela sua obtenção de forma sistemática e em quantidades significativas. 
Relativamente às técnicas empregues na exploração destes núcleos, o talhe por pressão e por percussão indireta apresentam-se à partida como os mais prováveis, considerando o resultados obtidos noutros estudos tecnológicos (Carvalho 1998a; 2009a; 2012). Porém, são de difícil diferenciação entre si no material debitado, uma vez que resultam em morfologias com atributos em comum, designadamente as formas regulares de nervuras e bordos paralelos. Segundo vários autores que se têm dedicado ao estudo da debitagem por pressão ou percussão indireta, ou ambos (por exemplo, Binder 1987; Pelegrin 1984a; 1984b; Tixier et al. 1980; Tixier 1984), as peças produzidas por percussão indireta diferenciam-se pelos talões com bolbos nítidos, por vezes esquirolados; o talhe por pressão, por seu lado, resulta em bolbos reduzidos, quase sempre sem ondulações, acidentes de ultrapassagem e índices mais elevados de padronização morfométrica dos módulos de talhe. A análise dos produtos alongados em sílex do Meu Jardim permitiu desde logo eliminar a possibilidade haver peças debitadas por percussão direta, uma vez que não foram identificados os seus atributos característicos (pontos de impacto marcados, talões lineares ou esquirolados). Em contrapartida, observaram-se indicadores muito sugestivos da debitagem por pressão, tal como descrito nas secções anteriores: percentagens elevadas de peças com acidentes de ultrapassagem, formas e nervuras regulares, talões facetados, frequentemente com ausência de ondulações, e bolbos reduzidos.

Um dos caracteres que lança alguma luz sobre a tecnologia de produção destes suportes é o facto de, tal como já reconhecido noutras coleções (Carvalho 1998a), o talhe por pressão manual parecer produzir peças mais estreitas e delgadas, e o talhe por percussão indireta resultar em peças tendencialmente de maiores dimensões. A utilização do comprimento está normalmente comprometida devido aos seus elevados índices de fragmentação, intencional ou pós-deposicional, que impede a obtenção desta medida de forma sistemática. Deste modo, os padrões de variação dimensional dos suportes alongados do Meu Jardim só podem ser abordados através da dispersão dos valores das larguras e espessuras, conquanto se trate de uma opção metodológica que acarreta um elevado nível de imprecisão (Figure 8).

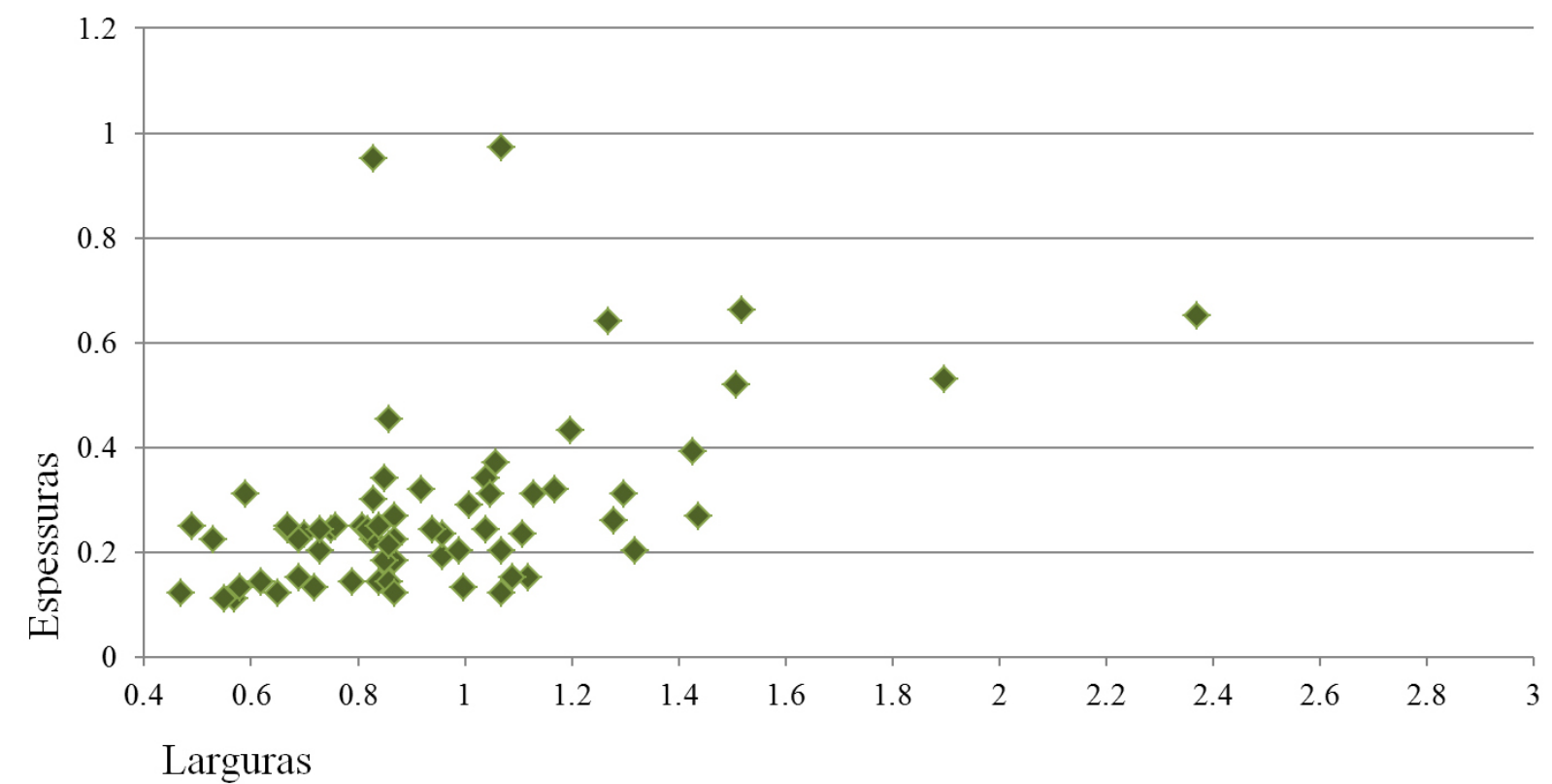

Figura 8. Dispersão das larguras e espessuras $(\mathrm{em} \mathrm{cm}$ ) dos produtos alongados em sílex (brutos, retocados e com sinais de uso).

Figure 8. Plotting of widths and thicknesses (in $\mathrm{cm}$ ) of flint blades or bladelets (unretouched, retouched and with use wear). 
Esta análise sugere a eventual coexistência de duas técnicas de debitagem neste concheiro. Com efeito, pode observar-se uma mancha mais densa de peças estreitas (larguras entre 0,4 e 1,19 cm) e delgadas (espessuras de 0,1-0,49 cm), as quais terão sido possivelmente debitadas por pressão manual, a par de um conjunto, menos numeroso e menos padronizado em termos métricos, de peças mais largas $(1,2-2,4 \mathrm{~cm})$ e espessas $(0,5-1 \mathrm{~cm})$, eventualmente debitadas por percussão indireta. Na faixa dos 0,8-1,2 cm de largura e 0,1-0,49 $\mathrm{cm}$ de espessura existe uma sobreposição entre ambos os agrupamentos. Este quadro métrico geral está assim em consonância com observações anteriores sobre contextos do Neolítico antigo em que as duas técnicas coexistem nos mesmos conjuntos, mas com um predomínio mais acentuado da debitagem por pressão, com recurso a tratamento térmico.

\section{Discussão: produção e circulação de suportes alongados em sílex no Neolítico Médio da Estremadura Portuguesa}

Embora se disponha de um quadro de referência já relativamente sólido para as indústrias líticas da fase antiga do Neolítico estremenho (por exemplo, Carvalho 1998a), as fases mais tardias deste período apresentam bastantes incógnitas, uma vez que a maioria dos estudos se foca em classificações tipológicas de produtos acabados. Todavia, está assente desde há muito a noção de que as produções laminares tendem a apresentar um progressivo robustecimento ao longo do Neolítico (Carvalho 1996; Zilhão 1994). Embora esse robustecimento tenha uma maior notabilidade a partir do Neolítico final, é durante o Calcolítico que as lâminas atingem grandes dimensões (acima de $2 \mathrm{~cm}$ de largura e comprimentos que podem atingir os $30 \mathrm{~cm}$ ), o que se deverá ao surgimento do talhe por pressão com alavanca (Carvalho 2009b).

Atualmente, o estudo da produção e circulação de suportes alongados no Neolítico Médio da região tem recebido algumas contribuições a partir de dados de contextos funerários, que têm providenciado uma primeira caracterização morfométrica e tecnológica. Em concreto, os conjuntos das grutas-necrópoles do Lugar do Canto (Cardoso \& Carvalho 2008) e do Algar do Bom Santo (Carvalho 2009b) (Figure 1, map B), ambas datadas de inícios ou meados do IV milénio a.n.e., revelaram resultados similares, apesar do número reduzido de peças analisadas (19 e 32 exemplares, respetivamente). Com efeito, foi possível identificar a existência de dois conjuntos morfométricos distintos: um, mais numeroso, formado por peças de pequenas dimensões (comprimentos de 2,5-10 cm e larguras de 0,8-2 $\mathrm{cm}$ ), e outro formado por lâminas robustas (comprimentos de 12-18 cm e larguras de 1,8-2,8 $\mathrm{cm}$ ). A ausência de tratamento térmico no grupo de maiores dimensões é também uma diferença assinalável entre ambos. Segundo Carvalho (2009b), estaremos em ambos os casos na presença de processos de debitagem por percussão indireta, não se podendo, no entanto, excluir a possível presença de talhe por pressão.

Até momento, apenas dois contextos não funerários apresentaram conjuntos suficientemente numerosos para permitir comparações entre si: o concheiro do Meu Jardim, tratado no presente texto (ver também Goufa 2014), e o Cerradinho do Ginete (Nunes 2014) (Figure 1, map B). Neste último sítio analisaram-se 39 lâminas e lamelas em sílex (das quais 10 retocadas), com índices de fragmentação muito elevados e alguma heterogeneidade morfológica geral. Predominam peças de formatos irregulares, perfis longitudinais direitos e secções transversais triangulares, bolbos nítidos sem ondulações, e talões lisos. Todavia, regista-se também a presença de talhe bipolar (há núcleos desta tipologia e uma componente de lamelas torcidas, de formas irregulares e talão esmagado). Outro aspeto a assinalar é a quase ausência de tratamento térmico, estando presente apenas em 15\% do material.

Relativamente aos atributos métricos, no Cerradinho do Ginete, tal como no Meu Jardim, predominam peças de pequenas dimensões, com comprimentos de 1,69-6,72 cm, larguras de $0,4-2,8 \mathrm{~cm}$ e espessuras de $0,1-0,97 \mathrm{~cm}$. Da análise comparada dos padrões morfométricos 
dos produtos alongados destes dois sítios (Figure 9) parece poder concluir-se que o talhe por percussão indireta estará também presente no Cerradinho do Ginete, estando testemunhado porventura pelas peças de larguras superiores a $1,4 \mathrm{~cm}$.

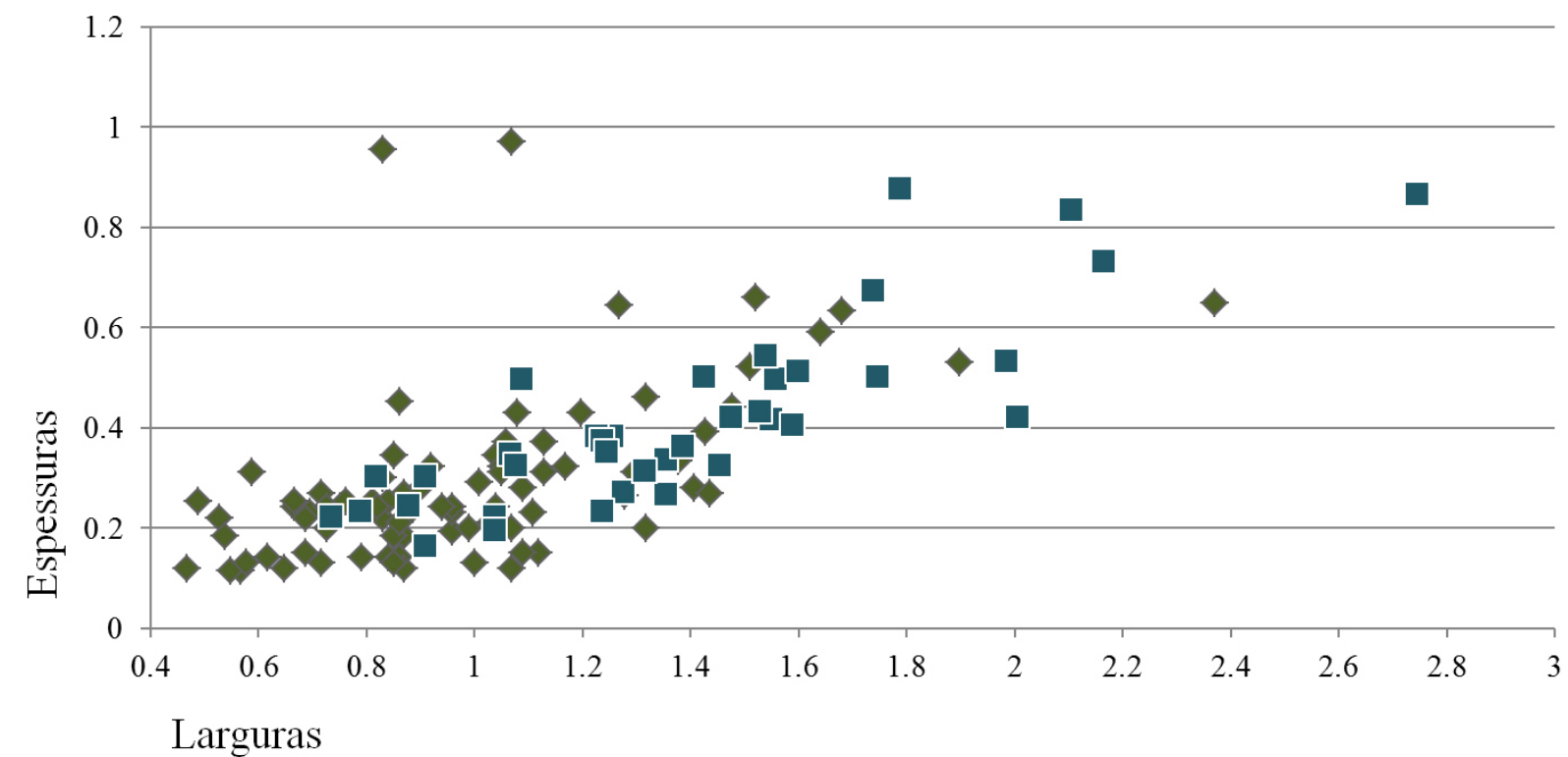

Figura 9. Variação da dispersão das larguras e espessuras $(\mathrm{em} \mathrm{cm}$ ) dos produtos alongados (em bruto, retocados e com sinais de uso) em sílex dos sítios de habitat do Meu Jardim (losangos verdes) e Cerradinho do Ginete (quadrados azuis).

Figure 9. Plotting of widths and thicknesses (in $\mathrm{cm}$ ) of blades or bladelets (unretouched, retouched and with use wear) in flint from the habitation sites of Meu Jardim (green diamonds) and Cerradinho do Ginete (blue squares).

Relativamente à circulação dos suportes alongados em sílex durante este período, os dados deixam entrever a possibilidade de terem existido estratégias de importação a partir dos sectores regionais onde o sílex é mais abundante e, porventura, também com melhor aptidão para o talhe. De facto, como referido atrás, o sílex distribui-se de forma desigual por toda a região. No interior do Maciço Calcário Estremenho - onde se localiza o Cerradinho do Ginete - o sílex é uma rocha rara (Aubry et al. 2014; Carvalho 2003; Zilhão 1997) e ocorre sobretudo sob a forma de nódulos de pequenas dimensões. Ao contrário do Meu Jardim, que se localiza numa área onde o sílex é de fácil obtenção, as limitações geológicas das áreas envolventes do Cerradinho do Ginete, Bom Santo e Lugar do Canto terão assim obrigado ao desenvolvimento de estratégias de circulação de suportes laminares.

O número reduzido ou completa ausência de material de desbaste e manutenção (lascas corticais, material de preparação e reavivamento de núcleos) e de núcleos em sílex, que se verifica de um modo geral nos sítios referidos, contrasta com o domínio de lâminas e lamelas de "fase plena" de debitagem. Este padrão reforça a hipótese da existência de processos de importação de suportes acabados para sítios onde o sílex é raro ou inexistente. Apesar de ainda não terem sido identificadas "oficinas de talhe" claramente datáveis deste período na região, os traços gerais da indústria de pedra lascada do Meu Jardim (Tables 1 and 2), que se localiza nas proximidades de formações siliciosas, parecem efetivamente confirmar sua existência. Mais ainda, parece também poder concluir-se desta indústria que as etapas iniciais do talhe do sílex (desbaste do córtex dos nódulos, pré-configuração dos núcleos, etc.) teriam lugar no próprio local de aprovisionamento da matéria-prima. Este padrão de comportamento, que resulta no abandono de material de talhe incaracterístico (lascas corticais, blocos testados, fragmentos informes) nas próprias jazidas de sílex, é responsável em grande medida pela dificuldade de reconhecimento das “oficinas de talhe” nesta época. 


\section{Considerações finais}

O estudo do importante conjunto lítico do concheiro do Meu Jardim vem reforçar a variabilidade de opções e estratégias de gestão do sílex - e, em particular, do talhe laminar que estudos recentes têm vindo a assinalar para o Neolítico Médio da Estremadura Portuguesa. Efetivamente, se o sítio do Cerradinho do Ginete (Nunes 2014) já pré-anunciava um contraste muito vincado entre contextos habitacionais e funerários, os dados recémadquiridos do Meu Jardim confirmam-no plenamente.

Os contextos funerários de gruta estudados em moldes modernos - Lugar do Canto (Cardoso \& Carvalho 2008) e Algar do Bom Santo (Carvalho 2009b) - revelam produtos relativamente robustos, com uma forte normalização morfológica, e em que a técnica da percussão indireta parece ser exclusiva. É seguro afirmar que estes conjuntos são formados por peças selecionadas deliberadamente para se constituírem como oferendas funerárias. Porém, o Cerradinho do Ginete revelara uma tendência para o domínio quase exclusivo de lamelas de muito pequenas dimensões e morfologias irregulares, algumas produzidas por debitagem bipolar, que aparentam ter sido debitadas a partir de pequenos volumes de sílex. Alguns módulos de dimensões superiores, que aparecem sobretudo sob a forma de fragmentos mesiais ou que serviram de suporte para micrólitos geométricos, são o único testemunho da existência original de produtos lâmino-lamelares que, ao que tudo indica, foram transportados em bruto para este sítio e aí utilizados até à exaustão. Tratar-se-ão de módulos equivalentes aos de menores dimensões encontrados nas grutas-necrópole. Este comportamento económico refletirá a escassez (ou, pelo menos, a não exploração) de sílex nas proximidades do sítio arqueológico.

O Meu Jardim mostra-nos uma situação distinta. Desde logo, a proximidade de jazidas de sílex deixava antever estratégias de exploração oportunistas ou expeditas, nunca de curação (sensu Binford 1979) como no caso no Cerradinho do Ginete, o que se veio a confirmar em pleno neste estudo. No entanto, diferentemente do sítio torrejano, não há no Meu Jardim uma componente bipolar que tenha tido impacto no perfil lâmino-lamelar desta indústria. Muito provavelmente, terá sido a proximidade de jazidas de sílex o fator que obviou a esta opção tecnoeconómica. Por outro lado, ainda em sentido contrário ao observado no Cerradinho do Ginete, no Meu Jardim também não há indício da importação de produtos alongados acabados de morfologias regulares. Há, sim, uma utilização "suficiente” de um recurso de fácil aquisição e que supria necessidades circunstanciais relacionadas com o estabelecimento recorrente e programado de um grupo humano neste local. Apenas através do estudo arqueológico das jazidas de sílex do território envolvente - que nunca foi feito de forma sistemática - se poderá esclarecer em definitivo a relação entre estas e o Meu Jardim e, em última instância, o seu papel na circulação de sílex durante o Neolítico da Estremadura Portuguesa.

\section{Agradecimentos}

Queremos deixar expressos os nossos agradecimentos aos dois revisores anónimos que contribuíram para melhorar diversos aspetos do nosso manuscrito original. Qualquer erro ou omissão é, no entanto, da nossa responsabilidade. 


\section{Referencias}

Binder, D., 1987 (Ed.), Le Néolithique ancien provençal. Typologie et technologie des outillages lithiques, 24, Suppléments à Gallia Préhistoire, Paris, 205 p. (in French; em Francês) ("The Early Neolithic in Provence. Typology and technology of the lithic tools”; “O Neolítico antigo provençal. Tipologia e tecnologia das utensilagens líticas”)

Binford, L., 1979, Organization and formation processes: looking at curated technologies. Journal of Archaeological Method and Theory, 35(3): 57-100. (in English; em Inglês) ("Processos de organização e formação: olhando para uma seleção de tecnologias ”) doi:10.1086/jar.35.3.3629902

Cardoso, J.L. \& Carvalho, A.F., 2008, A Gruta do Lugar do Canto (Alcanede) e sua importância no faseamento do Neolítico no território português. Estudos Arqueológicos de Oeiras, 16: 269-300. (in Portuguese; em Português) ("The Lugar do Canto Cave (Alcanena) and its importance in the phasing of the Neolithic in Portuguese territory")

Carvalho, A.F., 1996, O talhe da pedra e a transição Neolítico-Calcolítico no Centro e Sul de Portugal: tecnologia e aspectos da organização da produção. Trabalhos de Arqueologia da E.A.M., 3-4 (1995-1996): 41-60. (in Portuguese; em Português) ("Knapping stone and the Neolithic-Chalcolithic transition in Centre and South Portugal: technology and aspects of the organization of production")

Carvalho, A.F. 1998a, Talhe da pedra no Neolítico antigo do Maciço Calcário das Serras d'Aire e Candeeiros (Estremadura Portuguesa). Um primeiro modelo tecnológico e tipológico. Colibri, Lisboa, 110 p. (in Portuguese; em Português) ("Knapped stone in the Early Neolithic of the limestone massif of the Aire and Candeeiros mountains (Portuguese Estremadura)”) doi:10.2307/27924082

Carvalho, A.F. 1998b, O Abrigo da Pena d'Água (Rexaldia, Torres Novas): resultados das campanhas de sondagem (1992-1997). Revista Portuguesa de Arqueologia, 1(2): 39-72. (in Portuguese; em Português) ("Pena d'Água Rock-shelter (Rexaldia, Torres Novas): results of the test seasons (1992-1997)”)

URL: http://www.patrimoniocultural.gov.pt/media/uploads/revistaportuguesadearqueol ogia/1_2/1234/4.pdf

Carvalho, A.F., 2003, O Neolítico antigo no Arrife da Serra d’Aire. Um case-study da neolitização da Média e Alta Estremadura Portuguesa. Muita gente, poucas antas? Origens, espaços e contextos do Megalitismo. In: Actas do II Colóquio Internacional sobre Megalitismo (Gonçalves, V.; Sousa, A. \& Faria, A., Eds.), Instituto Português de Arqueologia, Lisboa: p. 135-154. (in Portuguese; em Português) ("The Early Neolithic in the Arrife of the Aire Mountain. A case-study of the Neolithisation of the Middle and Upper Portuguese Estremadura”)

URL: http://www.patrimoniocultural.gov.pt/media/uploads/trabalhosdearqueologia/25/9 .pdf

Carvalho, A.F., 2008, O talhe da Pedra na Pré-História recente de Portugal: 1. sugestões teóricas e metodológicas para o seu estudo. Praxis Archaeologica, 3: 167-181. (in Portuguese; em Português) ("Stone knapping in the Late Prehistory of Portugal: 1. theoretical and methodological suggestions for its study")

Carvalho, A.F., 2009a, O talhe da Pedra na Pré-História recente de Portugal: 2. O estado actual da investigação. Praxis Archaeologica, 4: 67-91. (in Portuguese; em Português) ("Stone knapping in the Late Prehistory of Portugal: 2. current state of the research") 
Carvalho, A.F., 2009b, O final do Neolítico e as origens da produção laminar calcolítica na Estremadura Portuguesa: os dados da gruta-necrópole do Algar do Bom Santo (Alenquer, Lisboa). In: Les grans fulles de sílex. Europa al final de la Prehistòria (Gibaja, J.F., Terradas, X., Palomo, A. \& Clop, X., Eds.), Museu d’Arqueologia de Catalunya, Barcelona: p. 75-82. (in Portuguese; em Português) ("The end of the Neolithic and the origins of the Chalcolithic blade production in Portuguese Estremadura: data from the cave-burial of Bom Santo Cave (Alenquer, Lisbon)”)

Carvalho, A.F., 2012, Do Neolítico à Idade do Bronze. In: Introdução ao estudo da pedra lascada (Gibaja, J.F. \& Carvalho, A.F., Eds), Colibri, Lisboa: p. 91-106. (in Portuguese; em Português) ("From the Neolithic to the Bronze Age")

Dinis, J., Henriques, M.V., Freitas, M.C. \& Andrade, C. 2005, The Holocenic evolution of the Óbidos, Alfeizerão and Pederneira lagoons (Western Portugal). Natural and anthropic forcing. In: Proceedings of the Iberian Costal Holocene Palaeoenvironmental Evolution, (Freitas, M. \& Drago, T. Eds.), Universidade de Lisboa, Lisboa: p. 42-43. (In English; em Inglês) ("Evolução Holocénica nas lagoas de Óbidos, Alfeizerão e Pederneira (Portugal Ocidental). Alterações naturais e antrópicas”)

Goufa, E., 2014, O sítio do Meu Jardim (Nazaré): contribuição para o estudo da pedra lascada no Neolítico Médio da Estremadura. Master's thesis at Faculty of Human and Social Sciences, University of Algarve, Faro, 200 p. (in Portuguese; em Português) ("The site of Meu Jardim (Nazaré): contribution to the study of knapped stone in the Middle Neolithic of Portuguese Estremadura”) doi:10.13140/RG.2.1.3366.2881

Henriques, M.V. \& Dinis, J., 2005, Avaliação do enchimento sedimentar holocénico na planície aluvial da Nazaré (Estremadura Portuguesa). In: Actas do X colóquio ibérico de Geografia, Associação Portuguesa de Geógrafos, Lisboa. (in Portuguese; em Português) ("Evaluation of the Holocene sedimentary infill of the Nazaré alluvial plain (Portuguese Estremadura)")

URL: http://www.apgeo.pt/files/docs/CD_X_Coloquio_Iberico_Geografia/pdfs/079.pdf

Nunes, A., 2014, Estudo dos materiais provenientes do Cerradinho do Ginete (Torres Novas, Santarém): contribuição para o estudo do Neolítico médio português. Master's thesis at Faculty of Human and Social Sciences, University of Algarve, Faro, 126 p. (in Portuguese; em Português) ("Study of the materials from Cerradinho do Ginete (Torres Novas, Santarém): contribution for the study of the Middle Neolithic in Portugal”) URL: https://sapientia.ualg.pt/handle/10400.1/6875

Pelegrin, J., 1984a, Approche technologique expérimentale de la mise en forme de nucléus pour le débitage systématique par pression. In: Préhistoire de la pierre taillée. 2. Économie du débitage laminaire: technologie et expérimentation (Tixier, J. Ed.), Cercle de recherches et d'études préhistoriques, Paris, p. 93-104. (in French; em Francês) ("Abordagem experimental da formatação de núcleos para a debitagem sistemática por pressão"; "Technological and experimental approach to core shaping for systematic pressure knapping”)

Pelegrin, J., 1984b, Systèmes expérimentaux d’immobilisation du nucléus pour le débitage par pression. Préhistoire de la pierre taillée. 2. Économie du débitage laminaire: technologie et expérimentation (Tixier, J. Ed.). Cercle de recherches et d'études préhistoriques, Paris, 117-128. (in French; em Francês) ("Sistemas experimentais de imobilização do núcleos para a debitagem por pressão"; "Core immobilisation experimental systems for pressure debitage”) 
Tixier, J., 1984 (Ed.), Préhistoire de la pierre taillée. 2. Économie du débitage laminaire: technologie et expérimentation. CREP, Paris: p. 13-19. (in french; em francês) ("PreHistória da pedra lascada. II. Economia de debitagem laminar: tecnologia e experimentação"; Prehistory of the knapped stone. II. Laminar debiting economy: technology and experimentation”)

Tixier, J., Inizan, M. L. \& Roche, H., 1980 (Eds.), Préhistoire de la Pierre Taillée. I. Terminologie et technologie. Cercle de Recherches et d'Études Préhistoriques, Antibes, 120 p. (in french; em francês) ("Pré-História da pedra lascada. I. Terminologia e tecnologia”; "Prehistory of the knapped stone. I. Terminology and technology”)

Valera, A.C. \& Santos, H., 2010, O concheiro do Neolítico Antigo do "Meu Jardim” (Nazaré): informação preliminar. Apontamentos de Arqueologia e Património, 6: 21-27. (in Portuguese; em Português) ("The Early Neolithic shell-midden of "Meu Jardim" (Nazaré): preliminary information”) URL: http://www.niaera.org/publicacoes/doc_download/6-apontamentos-6

Zilhão, J., 1994, A oficina de talhe neo-calcolítica de Casas de Baixo (Caxarias, Vila Nova de Ourém). Trabalhos de Arqueologia da E.A.M., 2: 35-46. (in Portuguese; em Português) ("The Neo-Chalcolithic knapping site of Casas de Baixo (Caxarias, Vila Nova de Ourém)”)

Zilhão, J. (Ed.), 1997, O Paleolítico Superior da Estremadura Portuguesa. Colibri, Lisboa, 1160 p. (in Portuguese; em Português) ("The Upper Palaeolithic of Portuguese Estremadura”) 


\title{
The shell-midden of Meu Jardim (Nazaré) in the context of the production and exchange of blade or bladelet blanks in Middle Neolithic Portuguese Estremadura
}

\author{
Eliana Goufa ${ }^{1}$, António Carlos Valera ${ }^{2}$, António Faustino Carvalho ${ }^{3}$ \\ 1. CEAACP - Centro de Estudos de Arqueologia, Artes e Ciências do Património (pólo UAlg), Universidade do \\ Algarve, F.C.H.S., Campus de Gambelas, 8000-117 Faro, Portugal. Email: e.goufa.arq@gmail.com \\ 2. ICArEHB - Interdisciplinary Center for Archaeology and Evolution of Human Behaviour / Era-Arqueologia \\ Lda., Calçada de Santa Catarina, 9C, 1495-705 Lisboa, Portugal. Email: antoniovalera@era-arqueologia.pt \\ 3. Universidade do Algarve, F.C.H.S., Campus de Gambelas, 8000-117 Faro, Portugal. Email: afcarva@ualg.pt
}

\begin{abstract}
:
The archaeological site of Meu Jardim (municipality of Nazaré) is a shell-midden with several phases of occupation dated to the Middle Neolithic period. It is located near flint deposits, on the Atlantic seaboard of the Portuguese Estremadura. Its excavation, that took place in the context of salvage archaeology, was due to the building of a bridge. The fieldwork consisted of the excavation of three tests, comprising a total area of $102 \mathrm{~m}^{2}$.

Given the gap in knowledge that dominates the lithic studies of the Middle Neolithic period, it was decided to analyse its blade and bladelet productions (from Tests 1 and 3, where the lithic assemblages are more abundant) and integrate them in their regional context. In order to allow for the establishment of systematic inter-site comparisons, an explicit methodological option was the use of the same analytical protocols as employed elsewhere in the study of coeval sites in the region. These protocols consist mainly of the adoption of the proposals initially put forward by Tixier et al. (1980), which were adapted by Carvalho (1998a; 2008) to the Early and Middle Neolithic periods in Portugal.

Overall, the knapped stone assemblage from Meu Jardim totals 639 artefacts of locally available raw materials (flint, quartz and quartzite), which form an assemblage composed of cores and core maintenance products, flakes and debris, blades and bladelets and retouched tools. Flint is the most used raw material, which is due to its availability in the area surrounding the shell-midden. It should be noted that flint is an abiotic resource that can be found almost everywhere in Estremadura but it may be absent from more restricted areas within the region. This fact impacted the acquisition strategies during the period. In the case of Meu Jardim, this implied an expedient exploitation of the nearest flint sources to face the needs of short stays at the site, and the abandonment of nodules and cores in their early stages of reduction. The so-called "prismatic method" (see definition in Carvalho 1998a) was employed for the production of elongated blanks. On average, these ranged in 1.8-7.0 cm in length, $0.5-1.4 \mathrm{~cm}$ in width and $0.2-0.9 \mathrm{~cm}$ thick, thus forming a bladelet-sized assemblage. The knapping techniques may have been comprised of pressure and indirect percussion; however, according to published experimental evidence, the former technique seems to have been dominant. Indeed, the overwhelming presence of overhanging accidents, regular edges and ridges and faceted butts along with the small sizes evidenced by these blanks strongly points to this conclusion and suggests the presence of hand-knapping procedures (i.e., without the use of levers or similar devices). Tools types are composed mostly of side-retouched blades and bladelets; notches, denticulates, perforators and truncations are less well represented. Microliths were not found.

Contrasting with the relatively robust evidence available for the Early Neolithic period in Estremadura, little is known regarding the later stages of the period. The most evident feature is likely the increase in sizes of elongated blanks that is recognized in many assemblages dated to the Middle
\end{abstract}


and Late Neolithic. The morphometric and technological study of blanks from Middle Neolithic cemeteries in the region have reveal two main size groups: one of smaller sizes $(2.5-10.0 \mathrm{~cm}$ in length, $0.8-2.0 \mathrm{~cm}$ in width) and a more robust one (12.0-18.0 cm in length, 1.8-2.8 cm in width). One attribute also marks the difference between the two: the absence of heat treatment in the latter group. Up to now, the evidence from habitation contexts is less clear due to the lack of studies. However, all seem to indicate that at other habitation sites the elongated pieces are similar to those identified at Meu Jardim. A factor that introduces more variability in morphotechnic features is the presence at some sites of bipolar knapping for the production of very small and irregular bladelets, the so-called "bipolar method" (see definition in Carvalho 1998a). In these cases, larger blanks likely imported as finished products from sites located near flint sources are found along with the locally produced smaller, irregular ones. This strategy was not observed at Meu Jardim; indeed, this site is testimony of the opposite situation.

Overall, these inferences reveal a pattern of highly diversified economic and technological behaviours regarding flint exploitation and exchange in Middle Neolithic Estremadura.

Keywords: Neolithic; Portugal; blade; bladelet blanks; technology; flint 